DOI: 10.12731/2070-7568-2017-2-171-189

УДК 330.342

\title{
ТЕОРЕТИКО-МЕТОДОЛОГИЧЕСКИЕ ОСНОВЫ ИССЛЕДОВАНИЯ СОЦИАЛЬНО-ЭКОНОМИЧЕСКИХ СИСТЕМ В ПРОЦЕССЕ ТРАНСФОРМАЦИИ
}

\section{Шестаков Р.Б.}

\section{Состояние вопроса.}

Трансформация сочиально-экономических систем как особая форма системного движения, оставляет исследователям открытые вопросы во многом как благодаря неоднозначности понимания феномена, так и сложности самого исследуемого объекта трансформации (системы).

Материалы и/или методы исследования.

В работе использованы системный, эволючионный, историкологический и экономико-статистические подходы к исследованию изменений социально-экономических систем.

\section{Результаты.}

Для точной детерминациии системной трансформациии необходимо не только учитывать уровень метасистемы (например, мега-, макро или микроуровень), но и динамику системной эволюиии, ее историко-логический вектор. В методологическом аспекте базальной проблемой изучения феномена трансформации остаются факторный и количественно-качественньй анализ.

\section{Заключение.}

Лучшее понимание процесса трансформации необходимо для формирования эффективной экономической политики. Трансформация российской экономики остаётся актуальной задачей в плане модернизации и переходу к новому технологическому укладу.

Ключевье слова: сочиально-экономическая система; развитие; эволюция; трансформация; транзит; модернизация. 


\title{
THEORETICAL AND METHODOLOGICAL BASIS OF THE SOCIO-ECONOMIC SYSTEMS RESEARCH IN THE TRANSFORMING PROCESS
}

\author{
Shestakov R.B.
}

\section{Background.}

The socio-economic systems transformation as a special form of the system drive, puts open questions to researchers because of understanding ambiguity and complexity of the researched transformation object (System).

\section{Materials and/or methods.}

In this article the system, evolutionary, historical, logical and economic-statistical research approaches of socio-economic systems changes are used.

\section{Results.}

For the exact determination, we need to consider the level of metasystem (e.g. mega, macro or micro level) and the system evolution dynamics and its historical and logical vector. The basic methodological aspect of the transformation phenomenon research problem is its factors, quantitative and qualitative analysis.

\section{Conclusion.}

A better transformation process understanding is necessary for an effective economic policy creating. The transformation of the Russian economy remains a challenge in terms of modernization and transition to the new technological order.

Keywords: socio-economic system; development; evolution; transformation; transit; modernization.

После неоднозначного, но в достаточной степени результативного опыта рыночного транзита, российская экономика столкнулась с угрозой отставания от развитых стран и интенсивно развивающихся рынков в плане формирования нового технологического уклада. Назрела необходимость фундаментального пересмотра экономи- 
ческой политики в сторону новой структурно-институциональной трансформации. Целью данной работы является рассмотрение общих теоретических и методологиях основ трансформации социально-экономических систем, которые необходимо учитывать при разработке конкретных стратегий и мер экономических изменений.

Анализ социально-экономических систем и закономерности их эволюции требует целостного представления об объекте исследования, то есть использования системного подхода как такового. В общем понимании экономическая система - особым образом упорядоченная система связей между производителями и потребителями материальных и нематериальных благ и услуг [28, с. 33]. Кроме того, экономическую систему можно также описать как совокупность всех экономических процессов, совершающихся в обществе на основе сложившихся в нем отношений собственности и хозяйственного механизма [27, с. 38]. Также возможно определение экономической системы, как сложной вероятностной динамической системы, охватывающей процессы производства, обмена, распределения и потребления материальных и других благ, функционирующую во взаимодействии с внешней средой или как форму организации экономики, хозяйственный механизм, предназначенный для нахождения путей и методов эффективного использования производственных ресурсов [25, с. 58]. Суммируем, что термин «экономическая система» органически соединяет в себе категории «система» и «экономика», имея в виду множество элементов (экономических субъектов и объектов), соединённых экономическими отношениями. Универсальный закон редкости ресурсов действует во всех экономических системах независимо от типа и исторического периода. В результате проблема эффективного использования ресурсов и их распределения тесно связана с основными задачами управления экономическими системами. Понятие «экономическая система» является более широким, чем понятие «способ хозяйствования». Каждой экономической системе присущ определенный доминирующий способ хозяйствования (например, основанный на действии рыночного механизма). 
В современной теоретической экономике важное значение приобретает социальная составляющая общественной системы (социальная система), образуя понятие системы «социально-экономической». Еще в 60-е гг. 20 века В.Я. Ельмеевым обосновывается концепция сочетания экономического и социального развития, создается теория и практика социального планирования, с этого момента термин «социально-экономический» становится весьма распространенным. Социальная система является взаимным отражением экономической системы, как и экономические действия (экономические отношения) субъектов есть форма социального действия [19, с. 74] (по В.В. Радаеву). Социальная система усложняет экономическую (которую можно абстрагировать до совокупности рациональных агентов, максимизирующих свою полезность и выгоду), институциональными элементами, как-то правовая среда, культура хозяйствования, неформальные отношения, качество человеческого капитала и др. В социальной компоненте зачастую лежат «ключи» к эффективности управления экономической системой, производной от неформальной институциональной структуры, взаимодействия людей и общего контроля, самодисциплины и возможностей творческого роста, соответствия структуры людям и т.п. [17].

На основе синтеза, мы предлагаем определить социально-экономическую систему как объединение множеств элементов и связей экономической и социальной подсистем (формула 1), (рис. 1):

$$
S S \cup E S=S E S,
$$

где SES - сочиильно-экономическая система

$S S$ - сочиальная система

ES - экономическая система

Классификационные подходы к социально-экономическим системам чаще базируются на пространственно-временной, эволюционно-интеллектуальной и технологической основе. Рассмотрим для начала так называемый формационный подход, затрагивающий длительный период общественного развития. Общественно-экономическая формация - качественно-определенный, исторически 
конкретный тип общественной системы, объединяющий способы производства, науки и искусства, многообразие духовной сферы, бытовых отношений и образа жизни в целом [14, с. 265].

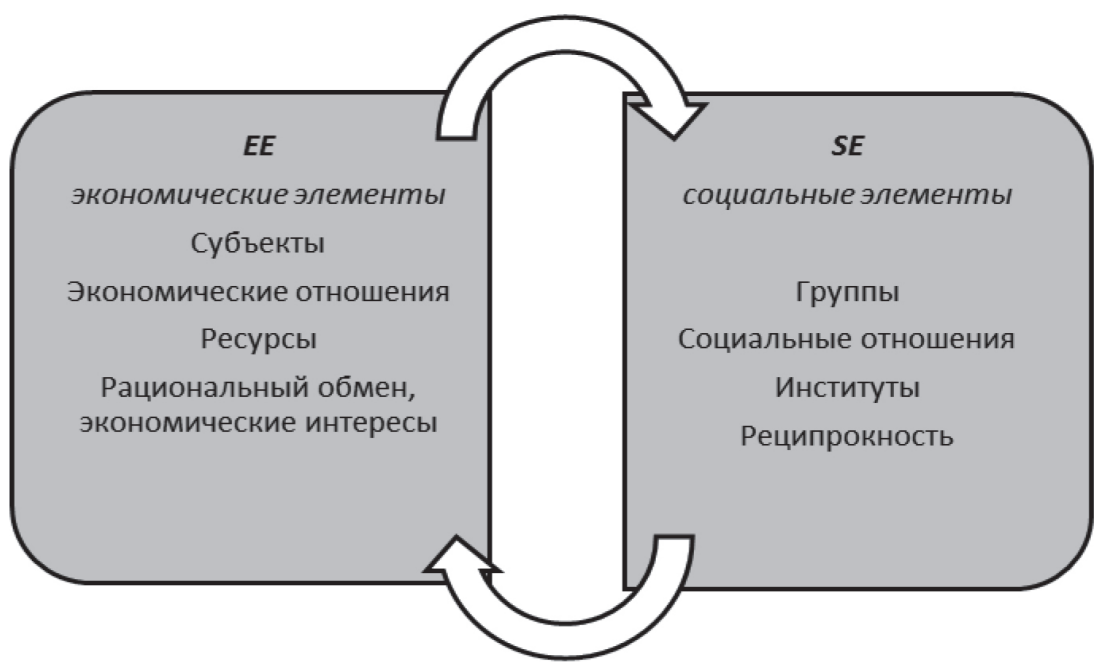

Рис. 1. Компонентная конвергенция социально-экономической системы

К. Маркс описывал структуру общественно-экономической формации с позиций «базиса» и «надстройки», чтобы объяснить, как производственные отношения определяют другие аспекты общества (политические, правовые и др.), и наоборот, как они воздействуют на экономическое развитие [14]: первичную (архаичную), куда он относил первобытнообщинный и азиатский способы производства; вторичную, основанную на частной собственности (рабство, крепостничество, капитализм); коммунистическую (коммунизм есть не «идеальный способ производства», как многие представляли, а историческая эпоха, включающая целый ряд способов производства, основным содержанием которой является уничтожение частной собственности). Также Маркс насчитал три производственные системы - кустарную, мануфактурную, машинно-индустриальную.

В отличие от социально-экономической категории формации, цивилизационный подход определяется с социокультурных позиций. 
Цивилизационный подход Э. Тоффлера предполагал следующее деление: аграрная - при переходе к земледелию; индустриальная - во время промышленной революции; информационная - при переходе к обществу, основанному на знании (постиндустриальному). Схожее деление, но уже с технологических позиций, содержится в теории Д. Бэлла [12], который делит общество на доиндустриальную, индустриальную и постиндустриальную стадии. Когда одна стадия приходит на смену другой, изменяются технология, способ производства, форма собственности, социальные институты, политический режим, культура, образ жизни, численность населения, социальная структура общества. М. Кастельс в работе «Информационная эпоха: экономика, общество и культура» [31] придерживается такого методологического подхода: общества организованы вокруг процессов человеческой деятельности, детерминированных в отношениях производства, опыта и власти. Он характеризует общество по двум признакам: 1) способ производства (капитализм, этатизм); 2) способ развития (индустриализм, информационализм).

Таким образом, социально-экономическую систему можно классифицировать с точки зрения превалирующего в настоящий момент технологического уклада. Современные российские ученые (С.В. Глазьев, Ю.В. Яковец, Д.С. Львов) определяют технологический уклад как совокупность построенных на основе общих технологических принципов технических систем, поколений техники и технологии, которые определяют эффективность экономической системы на определенном этапе развития, процесс их последовательного замещения.

По словам Карлоты Перес, в современных условиях, важно осознавать взаимосвязь между экономическим развитием и основными инновациями, техническими и системными изменениями [31]. Например, норвежский экономист Э. Райнерт, объясняя дифференциацию в развитии государств исходит из предпосылок величины инвестиций в инновации и уровня открытости экономики. Причем большую роль играет внешнее окружение, и открытость экономики будет играть положительную роль только при взаимодействии со странами схожего уровня, обратная ситуация будет 
только усугублять положение [20]. Интересной для понимания современной ситуации является классификация национальных экономик, которую в своем труде «Почему нации терпят неудачу» [35] обозначили профессора Массачусетского технологического института Дж. Робинсон и Д. Асемоглу. Они разделяют страны всего на две группы: «экстрактивные» (элита и население разделены, страна живет, в основном, за счет природной ренты) и «инклюзивные» (нет социального разделения, экономика основана на инновациях). Другими словами, качество технологического развития связано с качеством институтов социально-экономической системы.

При международных сопоставлениях различные международные организации имеют свои методики классификаций, применяя группировки по агрегированным показателям, географическому положению и т.д. Так, Всемирный Банк классифицирует страны по регионам развития (Восточно-азиатский и Тихоокеанский регион, Европа и Центральная Азия, Латинская Америка и «Карибы», Ближний Восток и Северная Африка, Южная Африка и Африканские страны ниже Сахары), по уровню доходов (высокий, средний, низкий и т.п.), отдельные группировки (Арабский мир, Евросоюз, беднейшие страны, зоны конфликтов и др.) и малые государства [34].

Социально-экономические системы могут состоять из подсистем в зависимости от уровня анализа (наиболее употребительно деление на нано-, микро-, мезо-, макро- и мегауровень). Для каждого из этих уровней характерно наличие типового социально-экономического объекта изучения (по Г.Б. Клейнеру) [10]: для мегаэкономического уровня таким объектом является мировая экономика; для макроэкономики - государство (страна); для мезоэкономики регион или отрасль; для микроэкономики - предприятие или домохозяйство; для наноэкономики - индивид. В современной системе социально-экономических институтов каждый из этих объектов является не только относительно обособленным экономическим объектом, но и субъектом, способным принимать самостоятельные решения, обладающим определенным набором прав и несущим ответственность перед другими субъектами. 
Кроме уровневой структуры, необходимо учитывать и общие функции (характерны практически для всех уровней, с незначительными вариациями), которые отражают экономические отношения: организационный, социальный, воспроизводственный, и, мы еще отдельно выделяем функцию поддержки экономической активности субъектов, так как, по нашему мнению, она лежит в основе организационных, воспроизводственных и социальных процессов. Экономическая активность системных субъектов - источник движения социально-экономической системы. При современном типе хозяйствования, большое значение приобретает деловая активность, тесно связанная с инновационными преобразованиями, а ядром деловой активности становиться активность предпринимательская. Такой специфический институт как малое предпринимательство помимо всего прочего является и носителем важной социальной функции, и из-за своих особенностей, требует особого внимания в плане дифференцированной поддержки государства [13].

В дополнение понятийно дифференцируем термины «система» и «организация». Организация выступает как свойство (внутренняя упорядоченность взаимодействий) системы, процесс или совокупность процессов (образование и совершенствование взаимосвязей между частями целого) и организационной системы (объединение людей для достижения цели на основе определенных механизмов функционирования) [16, с. 4]. Таким образом, в широком смысле «организация» - это свойство систем, а в узком - действие, направленное на создание чего-либо (например, организация собственного бизнеса). Кроме того, организацией можно назвать группу людей, объединившихся ради достижения общих целей (например, бизнесорганизация) [18, с. 10]. Организации возможно считать открытыми системами, потому что они динамично взаимодействуют с внешней средой [17, с. 297], что, в основном, характерно для микроэкономического системного уровня. В институциональном анализе понятие организации тождественно контрактной сети. Как отмечает И.В. Кирьянов [9, с. 124-125] организации присуще стремление к расширению. Этап «классической фирмы» - низкой степень интеграции 
элементов, объединением трансформационных единиц со схожим институциональным устройством, сменяется интегрированной группой с возрастающей степень интеграции элементов, увеличивающаяся за счет преимуществ нового институционального устройства.

В качестве обобщения дадим определение социально-экономической системы как многоуровневой иерархической структуры общества (метасистемы), объединяющей компонентные экономические и социальные подсистемы посредством социально-экономических отношений с целью реализации определенных функций, достижения определенного состояния и самоорганизации. Однако «статическое» определение всегда будет неполным без учета неотделимого свойства систем - движения. Высшей формой динамики системы является ее развитие, переход на качественно новый уровень существования. Экономическое развитие представляет собой многоплановое явление, отражающее экономический рост, структурные изменения в экономике и рост уровня и качества жизни [27, с. 894]. Транзит и трансформация сопряжены с развитием в качестве типов этого вида движения (в том числе изменчивости) в природе и обществе, перехода от одного качества к другому, от старого к новому. Необходимо различать понятие экономического развития и экономического роста. Последний представляет собой количественную, объемную сторону развития экономической системы, характеризующую изменение ее масштабов [12, с. 418-419]. Чаще всего для измерения используют показатели валового производства (ВВП, ВРП, валового дохода фирмы), в том числе в расчете на душу населения.

Развитие проходить по пути эволюции - процесса непрерывного постепенного изменения системы, ее параметров. В отличие от нее, революция - резкие, коренные и качественные изменения. Антитезисом развития является процесс деградации (инволюции), который может закончиться физическим разрушением системы. Эволюционный подход (Й. Шумпетер, К. Эрроу и др.) к изучению социально-экономических систем по аналогии эволюционной теории в биосистемах оперирует такими понятиями, как популяция объектов (в смысле популяции фирм, индивидуумов, марок товаров 
и т.п.). Моделируются и изучаются вхождение отдельных элементов в популяцию (их «зарождение»), взаимодействие, подверженность внешним воздействиям, выход из популяции («умирание»).

В словаре синонимов русского языка «трансформация» имеет значение «изменение» и «превращение». Трансформировать значит изменить [1, с. 502]. По мнению А.И. Колганова и А.В. Бузгалина, под трансформационными экономическими системами можно подразумевать экономики, в которых происходят качественные изменения в системе социально-экономических отношений, институтов и механизмов функционирования на микро- и макроуровнях [11, с. 483].

Интересной задачей является соотнесение понятий трансформация (трансформационный) и транзит (транзитный, транзитивный) в рамках процесса изменения социально-экономических систем. Термин «транзитивный» можно понимать, как переходный (Большой толковый словарь русского языка) [4, с. 1338]. Если рассматривать транзитивность с экономической точки зрения, то это состояние экономики в процессе трансформации, ацикличное преобразование экономических отношений, постоянный онтологический переход из одного качественного состояния в другое более прогрессивное [26, с. 17]. То есть, транзитом мы можем можно назвать движение по вектору целевого направления экономической трансформации, последовательную смену состояний системы (или целевое состояние), а собственно трансформацией - процесс количественных и качественных (структурных) изменений в самой системе. Говоря о переходной экономке, одновременно подразумевается транзитивная экономика (например, транзит от административной системы к рыночной) и трансформационная (процесс преобразование структуры и институтов). Транзит (переход) невозможен без трансформации системы, изменения как самих элементов, так и структуры, взаимосвязей и векторов развития. Можно предположить, что эволюция - долгосрочный транзит, а революция практически мгновенный (по историческим меркам).

Процесс системной трансформации предполагает определенный порядок в перестройке таких системных элементов как экономические отношения, структурно-институциональные связи 
систем управления. Трансформация социально-экономических отношений предполагает, прежде всего, изменения на основных фазах общественного воспроизводства (производства, обмена, распределения, потребления), включая отношения собственности, организационно-технические отношения. Новые социально-экономические отношения заставляют менять хозяйственную структуру и дает толчок адаптации институциональной составляющей. Так, в России переход к рыночным спросоориентированным отношениям постепенно изменял хозяйственную структуру (например, доля промышленности в ВВП за десятилетие активной перестройки сократилась с 39\% в 1991 году до 28\% в 2001 году [23, с. 25]). Структурные трансформации подразумевают изменения в воспроизводственной структуре, отраслевой структуре, технологической, институционально-экономической, стоимостной и внешнеэкономической. Под модернизацией, как мы считаем, надо понимать такой переходный процесс, когда системы трансформируются по определенному образцу (или концепции), где конечной целью ставится достижение подобия части или всей совокупности системы существующей передовой экономики (например, инновационный вектор развития по примеру постиндустриальных стран) [24, с. 91].

Трансформация институтов тесно взаимосвязана со всеми процессами изменений и предполагает изменение формальных и неформальных институтов. Отставание институциональных изменений от меняющихся отношений может затруднить транзитивный процесс, приводя к кризисным явлениям в экономике. Трансформация несет изменение основ классовой организации общества, обретением классовой структурой принципиально нового измерения. Возможны классовые конфликты между классом людей, обладающих наиболее значимым ресурсом и теми, кто не вошел в круг новой элиты. В результате переход к постиндустриальному обществу может стать периодом серьезной нестабильности в развитии цивилизации [22, с. 86]. В любом случае, главная цель системно-институциональных преобразований - создание действенных стимулов экономической активности людей, роста их благосостояния и уровня жизни. 
Трансформацию могут характеризовать коэффициенты интенсивности трансформации (КИТ), суммирующие структурные сдвиги за переходный период (Ю.В. Яковец). В зависимости от временных рамок преобразований коэффициент может изменяться от 10 до 40\%. Причем структура экономики не может измениться целиком, сохраняется наследственное ядро, модифицирующееся с переходом к новому структурному циклу [30, с. 225]. Также в качестве индикаторов трансформационного развития выделяют производительность труда, демографию бизнеса, эффективность использования капитала [2, с. 191]. Структурные сдвиги по крупным секторам хозяйства можно определить по последовательным рангам интегральной эффективности (рентабельность продукции и рентабельность активов) [23, c. 145-146]. Федеральная служба государственной статистики в разделе «Институциональные преобразования в экономике» перечисляет показатели, связанные со структурной статистикой предприятий, средними и малыми предприятиями (включая микропредприятия), индивидуальными предпринимателями, деятельностью организаций с участием иностранного капитала, демографией организаций, приватизацией государственного и муниципального имущества, бизнесдемографией. Для исследования институциональной трансформации можно также ориентироваться на синтетические индексы международных организаций, таких как ООН (индекс человеческого развития), Всемирный банк (рейтинг благоприятности ведения бизнеса), Всемирный экономический форум (глобальная конкурентоспособность), индексы крупных рейтинговых агентств и некоторые другие.

Современная трансформация экономических отношений связана с распространением интернет-технологий, глобальным аутсорсингом, преобразованием производственной структуры в рамках транснациональных корпораций как источников инноваций, финансовых систем [6, с. 72], то есть по сути тождественна переходу к новому технологическому укладу. Последующие трансформации сложны для прогнозирования и представления вообще (примером данной ситуации может служить теория технологической и экономической сингулярности по В. Вернору [34], предполагающая приближение к практически бесконечной скорости преобразований). 
Несмотря на кризисные системные явления, которые сопровождают процесс трансформации, оппозитной положительной «стороной медали» существующей ситуации является то, что нестабильность рождает волны инноваций, и чем сильнее проявляется нестабильность, тем более глубокими могут быть технологические сдвиги.

В качестве выводов отметим:

1. Для российской экономики актуальным и жизненно важным вектором транзита становиться направление на модернизацию и новый технологический уклад.

2. Экономический рост должен рассматриваться не как конечная цель, а инструмент развития, связанный с многими прямых и опосредованными факторами: структурно-институциональной трансформацией, цикличностью развития, наличием стимулов экономической активности и некоторых др.

3. Трансформация социально-экономической системы есть перманентный, объективный процесс изменения состояния элементов, их групп и взаимосвязей в системе, и является универсальной закономерностью развития.

4. Качество трансформации влияет на целевой транзитивный вектор общего развития системы, которая может иметь и отрицательное направление (деградация и возможное разрушение системы).

5. Оценивать трансформацию необходимо на динамическом ряду, так как трансформация есть форма движения социально-экономической системы. Скорость изменения показателей по сути является скоростью трансформации (трансформационная активность), а их изменчивость - глубиной трансформации. В эконометрическом аспекте это могут быть темпы роста и прироста, показатели вариации, тренды, коэффициенты мультипликации и др.

\section{Список литературы}

1. Александрова 3.Е. Словарь синонимов русского языка: Практический справочник: Ок. 11000 синоним. рядов. 11 изд., перераб. и доп. М.: Рус. яз., 2001. 568 с. 
2. Басовская Е.Н., Басовский Л.Е. Процессы и факторы кризисной трансформации экономики России. // Известия ТГУ. Экономические и юридические науки, 2013. №4-1. С. 191-198.

3. Беляева О.А. Использование компромиссов в управлении экономическими системами // Вестник Саратовского государственного технического университета. 2009. № 2 (38). С. 200-205.

4. Большой толковый словарь русского языка / Сост. и гл. ред. С.А. Кузнецов. СПб.: «Норинт», 2000. 1536 с.

5. Вечканов В.Э. Философия: курс лекций. Учебное пособие для вузов. М.: Изд-во «Экзамен», 2006. С. 320.

6. Дейнека Л.Н. Трансформация экономических отношений и проблемы ее отражения в современной экономической теории // Известия ЮФУ. Технические науки, 2012, №8. С. 71-79.

7. Дрогобыцкий. И.Н. Системный анализ в экономике: учебник для студентов вузов. М.: ЮНИТИ-ДАНА, 2012. 423 с.

8. Институциональная экономика: Учеб. пособие / Под рук. акад. Д.С. Львова. М.: ИНФРА-М, 2001. 318 с.

9. Кирьянов И.В. Трансакционные издержки, феномен торгового дома и экономическая организация // Journal of Institutional Studies. 2015. Т. 7. № 4. С. 112-127.

10. Клейнер Г.Б. Государство - регион - отрасль - предприятие: каркас системной устойчивости экономики России // Экономика региона, 2015. № 2. С. 50-58.

11. Колганов А.И., Бузгалин А.В. Экономическая компаративистика: Учебник. М.: ИНФРА-М, 2011. 746 с.

12. Лопатников Л.И. Экономико-математический словарь: Словарь современной экономической науки. М.: Дело, 2003. 520 с.

13. Мальцева Е.С. Проблемы и перспективы развития малого бизнеса в России // Бизнес и дизайн ревю. 2016. Т. 1. № 4 (4). С. 4.

14. Маркс К., Энгельс Ф. Из «Письма Вере Засулич». Соч. Т.19. С. 250-251. 15. Никоноров В.М. Классификации систем для управления // Наука Красноярья. 2016. №5 (38). С. 146-160.

16. Новиков Д.А. Методология управления. М.: Либроком, 2011. 128 с.

17. Оришев А.Б. Социологические теории управления: ретроспективный анализ // Бизнес и дизайн ревю. 2016. Т. 1. № 1 (1). С. 5. 
18. Производственный менеджмент: Учебник / Под ред. В.А. Козловского. М.: ИНФРА-М, 2003. 574 с.

19. Радаев В.В. Экономическая социология [Текст]: учеб. пособие для вузов; Гос. ун-т - Высшая школа экономики. М.: Изд. Дом ГУ ВШЭ, 2008. $602 \mathrm{c}$

20.Райнерт Э.С. Как богатые страны стали богатыми, и почему бедные страны остаются бедными. М.: Изд. дом Гос. ун-та - Высшей школы экономики, 2011. 384 с.

21.Рой О.В. Исследования социально-экономических и политических процессов: Учебник для вузов. СПб.: Питер, 2004. 364 с.

22. Рябкова С.А. Классовая трансформация в постиндустриальном обществе: причины и последствия // Наука Красноярья, № 4(37), 2016. С. 79-89.

23. Структурная и институциональная модернизация экономики России: секторальный анализ в контексте мирового развития / Отв. ред. Ю.В. Куренков; Ин-т мировой экономики и международных отношений РАН. М.: Наука, 2006. 415 с.

24. Шестаков Р.Б. Социально-экономическая модернизация институциональной матрицы // Общество и образование, 2014. №5 (88). С. 91-92.

25. Шишкин А.Ф. Экономическая теория: Учебное пособие для вузов. В 2 кн. Кн. 1. М.: Гуманит. изд. Центр ВЛАДОС, 1996. 656 с.

26. Шишкина Н.В. Вектор и эффективность транзитологической парадигмы АПК. Воронеж: Центрально-Черноземное книжное издательство, 2003. 483 с.

27.Экономика: Учебник / Под ред. Д.э.н., проф. А.С. Булатова. М: Юристь, 2002. 895 с.

28. Экономическая теория (политэкономия): Учебник / Под общей ред. Акад. В.И. Видяпина, акад. Г.П. Журавлевой. М.: ИНФРА-М, 1997. $560 \mathrm{c}$.

29. Яковец Ю.В. Эпохальные инновации XXI века / Международный институт П. Сорокина-Н. Кондратьева. М.: издательство «Экономика», 2004. 444 с.

30. Acemoglu D., Robinson J. Why Nations Fail: The Origins of Power, Prosperity, and Poverty. Crown Business Publications, 2012. 544 p. 
31. Bell D. The coming of post-industrial society: A venture of social forecasting. N.Y.: Basic Books, 1973.

32. Castells M. Information Age: Economy, Society and Culture. Vol. I-III. Oxford: Blackwell Publishers, 1998.

33. Perez C. Technological revolution and techno-economic paradigm. Working Papers in Technology Governance and Economic Dynamics no. $20.26 \mathrm{p}$.

34. Vernor V. The Coming Technological Singularity: How to Survive in the Post-Human Era. http://www.rohan.sdsu.edu/faculty/vinge/misc/singularity.html

35. The World Bank. Country and Economies 2014 [Электронный ресурс]: [сайт]. Режим доступа: http://data.worldbank.org/country

\section{References}

1. Aleksandrova Z.E. Slovar'sinonimov russkogo jazyka: Prakticheskij spravochnik: Ok. 11000 sinonim. rjadov [Synonyms dictionary of the Russian language: a practical handbook: about 11000 synonym series]. M.: Russian Language Publ., 2001. 568 p.

2. Basovskaja E.N., Basovskij L.E. Processy i faktory krizisnoj transformacii jekonomiki Rossii [Processes and factors of the Russian economy crisis transformation]. Izvestija TGU. Jekonomicheskie i juridicheskie nauki, 2013. №4, pp. 191-198.

3. Beljaeva O.A. Ispol'zovanie kompromissov v upravlenii jekonomicheskimi sistemami [The use of the trade-offs in an economic systems management]. Vestnik Saratovskogo gosudarstvennogo tehnicheskogo universiteta, 2009. № 2 (38). pp. 200-205.

4. Bol'shoj tolkovyj slovar'russkogo jazyka [A large dictionary of Russian language]. Compiler and editor S.A. Kuznecov. SPb. Norint publ, 2000. $1536 \mathrm{p}$.

5. Vechkanov V.Je. Filosofija: kurs lekcij [Philosophy lectures]: textbook for high schools] Moscow. Exams Publ., 2006. 320 p.

6. Dejneka L.N. Transformacija jekonomicheskih otnoshenij i problemy ee otrazhenija v sovremennoj jekonomicheskoj teorii [The transformation of the economic relations and the problem of its reflection in modern economic theory]. Izvestija JuFU. Tehnicheskie nauki, 2012, №8, pp. 71-79. 
7. Drogobyckij I.N. Sistemnyj analiz v jekonomike: uchebnik dlja studentov vuzov [System analysis in Economics: a textbook for university students]. Moscow. JUNITI-DANA Publ., 2012. 423 p.

8. Institucional'naja jekonomika [Institutional economics]: Stud. Manual. Under D.S. L'vov supervision. Moscow. INFRA-M Publ., 2001. 318 p.

9. Kiryanov I.V. Transakcionnye izderzhki, fenomen torgovogo doma i jekonomicheskaja organizacija [Transaction costs, the phenomenon of trade houses and economic organization]. Journal of Institutional Studies. 2015. Vol. 7. № 4, pp. 112-127.

10. Kleiner G.b. Gosudarstvo - region - otrasl' - predprijatie: karkas sistemnoj ustojchivosti jekonomiki Rossii [State-region-industry-enterprise: the frame of Russia economy system resilience]. Regional economy. 2015. № 2, pp. 50-58.

11. Kolganov A.I., Buzralin A.V. Jekonomicheskaja komparativistika: Uchebnik [Economic comparison: Textbook]. Moscow. INFRA-M, 2011. 746 p.

12.Lopatnikov L.I. Jekonomiko-matematicheskij slovar': Slovar'sovremennoj jekonomicheskoj nauki [Economic-mathematical dictionary: Dictionary of modern economics]. Moscow. Delo Publ., 2003. 520 p.

13. Mal'ceva E.S. Problemy i perspektivy razvitija malogo biznesa v Rossii [Problems and prospects of small business development in Russia]. Biznes i dizajn revju. 2016. Vol. 1. № 4 (4). P. 4.

14. Marks K., Jengel's F. Iz Pis'ma Vere Zasulich [From Letter to Vera Zasulich]. Vol. 19, pp. 250-251.

15. Nikonorov V.M. Klassifikatsii sistem dlya upravleniya [Classification of systems for management]. Nauka Krasnoyar'ya. 2016. №5 (38), pp. 146-160.

16. Novikov D.A. Metodologija upravlenija [The management methodology]. Moscow. Librokom Publ., 2011. 128 p.

17. Orishev A.B. Sociologicheskie teorii upravlenija: retrospektivnyj analiz [Sociological theory of management: a retrospective analysis]. Biznes $i$ dizajn revju. 2016. Vol. 1. № 1 (1). P. 5.

18. Proizvodstvennyj menedzhment [Production management]: Textbook. under V. A. Kozlovskiy editorship. Moscow. INFRA-M, 2003. 574 p. 
19. Radaev V.V. Ekonomicheskaja sociologija [The economic sociology: Textbook for high school]. Moscow. Dom GU VShE Publ., 2008. $602 \mathrm{p}$.

20. Reinert E.C. Kak bogatye strany stali bogatymi, i pochemu bednye strany ostajutsja bednymi [How Rich Countries Got Rich and Why Poor Countries Stay Poor]. Moscow. State House Publ. University High school of Economics, 2011. 384 p.

21. Roj O.V. Issledovanija social'no-jekonomicheskih i politicheskih processov [The socio-economic and political processes research]: Textbook for high school. SPb. Piter Publ, 2004. 364 p.

22. Rjabkova S.A. Klassovaja transformacija v postindustrial'nom obshhestve: prichiny i posledstvija [Class transformation in postindustrial society: causes and consequences]. Nauka Krasnojar ’ja, № 4(37), 2016, pp. 79-89.

23. Strukturnaja i institucional'naja modernizacija jekonomiki Rossii: sektoral'nyj analiz v kontekste mirovogo razvitija [Russian economy structural and institutional modernization: a sectoral analysis in the context of global development]. Under Ju.V. Kurenkov editorship. In-t mirovoj jekonomiki i mezhdunarodnyh otnoshenij RAN. Moscow. Nauka Publ., 2006. 415 p.

24. Shestakov R.B. Social'no-jekonomicheskaja modernizacija institucional'noj matricy [Socio-economic modernization of the institutional matrix]. Obshhestvo i obrazovanie, 2014. №5 (88), pp. 91-92.

25. Shishkin A.F. Jekonomicheskaja teorija [Econimics: Textbook fo high school]. Moscow. Gumanit. izd. Centr VLADOS, 1996. 656 p.

26. Shishkina N.V. Vektor i jeffektivnost' tranzitologicheskoj paradigmy $A P K$ [Vector and effectiveness of agrocomplex transiting paradigm]. Voronezh: Central'no-Chernozemnoe knizhnoe izdatel'stvo, 2003. $483 \mathrm{p}$.

27.Jekonomika [Economics]: Textbook. Under A.S. Bulatov editorship. Moscow. Jurist Publ., 2002. 895 p.

28.Jekonomicheskaja teorija (politjekonomija) [Economics (political economy)]: Textbook. Under V.I. Vidjapin and G.P. Zhuravleva editorship. Moscow. INFRA-M Publ., 1997. 560 p. 
29. Yakovets U.V. Jepohal'nye innovacii XXI veka [Landmark innovations of the 21st century]; International Institute of P. Sorokin- N.Kondratieff. Moscow, 2004. 444 p.

30. Acemoglu D., Robinson J. Why Nations Fail: The Origins of Power, Prosperity, and Poverty. Crown Business Publications, 2012. 544 p.

31. Bell D. The coming of post-industrial society: A venture of social forecasting. N.Y.: Basic Books, 1973.

32. Castells M. Information Age: Economy, Society and Culture. Vol. I-III. Oxford: Blackwell Publishers, 1998.

33. Perez C. Technological revolution and techno-economic paradigm. Working Papers in Technology Governance and Economic Dynamics no. $20.26 \mathrm{p}$.

34. Vernor V. The Coming Technological Singularity: How to Survive in the Post-Human Era. http://www.rohan.sdsu.edu/faculty/vinge/misc/singularity.html

35. The World Bank. Country and Economies 2014. http://data.worldbank. org/country

\section{ДАННЫЕ ОБ АВТОРАХ}

Шестаков Роман Борисович, доцент кафедры экономики и менеджмента в АПК

ФГБОУ ВО Орловский государственный аграрный университет имени Н.В. Парахина

ул. Генерала Родина, 69, г. Орел, 302019, Российская Федерация satynter@mail.ru

\section{DATA ABOUT THE AUTHORS}

Shestakov Roman Borisovich, Associate Professor of the Department of Economics and Management in the Agroindustrial Complex Orel State Agrarian University named after N.V. Parakhin 69, General Rodin Str., Orel, 302019, Russian Federation satynter@mail.ru

ORCID: 0000-0002-0797-5842

SPIN-code: 5097-1422 